\title{
CALCULATION OF TYRE NOISE RADIATION WITH A MIXED APPROACH
}

$43.40 \mathrm{R}$

Philippe JEAN; Jean-François RONDEAU, François GAUDAIRE

Centre Scientifique et Technique du Bâtiment, 24 rue Joseph Fourier, 38400 Saint Martin d'Hères

France

Jean@cstb.fr

\section{ABSTRACT}

The radiation of tyre noise is computed with a mixed integral/ ray tracing approach called GRIM. It is simply an integral over the vibrating tyre, of the product of the known velocity by the full Green function which takes into account all the multiple reflections and diffraction between tyre, ground and car body. This Green function is calculated by means of a beam tracing program named ICARE, which can deal with curved surfaces and multiple diffraction.

This approach makes the link between tyre models and certification points well outside the car.

\section{A DECOUPLED APPROACH}

The problem of sound radiation form tyres has recently gained the attention of many researchers. Several European projects are dedicated to this subject. RATIN (Radiation of Tire Noise) aims at the development of a comprehensive numerical solution by combining several approaches. Among the seven partners involved four are concerned by the prediction of tyre vibration (ISVR, Chalmers, $\mathrm{KTH}$,and Goodyear), each with a different approach. The role of CSTB is to predict sound radiation by means of the so-called GRIM : Green Ray Integral Method. [4]. The underlying idea is to express the sound pressure as a Rayleigh-like Integral on the vibrating tyre

$$
P(R)=j \omega \rho \int_{\text {tyre }} G(M, R) V(M) d S(M)
$$

where $V$ is the known velocity of the tyre(s) and $G$ is the Green solution when the tyres are assumed rigid; it includes the whole environment: ground, car ...etc.

This is an exact expression where $V$ and $P$ are coupled. It could be used in a classical FEM/BEM scheme with the main advantage of reducing the surface of integration to $S_{t y r e}$, leading to a matrix expression to solve. Fortunately in most air-like situations the assumption that the velocity can be estimated a priori is possible so that one simply ends up with a simple integration of two known quantities. $G$ is computed using the ray tracing program ICARE [5] which can deal with curved surfaces and diffracting wedges using the Uniform Theory of Diffraction. Multiple diffractions are possible. $V$ comes from the tyre models (analytical or numerical). 


\section{NUMERICAL RESULTS}

Since RATIN is still an undergoing project the first numerical validation has been made against $2.5 \mathrm{D}$ BEM calculations with the program MICADO [6,7]. 3D validations are under way and will use calculated velocities and real experiments as a reference. By $2.5 \mathrm{D}$ we mean that the tyre is placed in an infinite rigid cylinder but that source and receiver are points. Figure 1, shows this geometry and an example or rays obtained from ICARE. Figure 2 shows a validating example of ICARE. Figure 3 shows the variation of $G_{V}$ on the tyre with frequency and angular position. ICARE's calculations have been made without diffraction on the curved surface, so that no rays arrive behind the tyre and jumps can be seen as the angle varies from top to bottom and as the number of rays increase. The difference between MICADO and ICARE comes mainly from this effect, which can be corrected. Figure 4 shows a comparison of 2D BEM calculations between MICADO, SYSNOISE and KROPP's calculations [8] where MICADO and KROPP's results are in very good agreement. Very good results have also been made with a 3D BEM code developed at CSTB, compared to measurements.

Next, we assume a unit velocity on the baffled tyre. Figure 5a compares the GRIM's result and the reference BEM calculation; poor agreement is achieved. After analysis, the problem has been found to be due to the lack of precision of the Green functions calculated by ICARE at points very close to the contact point. The rays must reflect an increasing number of times as they reach the contact point and numerical precision problems occur. This is confirmed by Figure $\mathbf{5 b}$ which shows the result of the GRIM integration when carried by omitting the first 12 degrees on the tyre. Excellent agreement confirms the above mentioned problem. Note that omitting only 12 degrees changes significantly the integrated results which confirms the paramount role of the horn zone. This effect would even be more important for real velocity fields which have higher amplitudes in this region.

Two solutions have been considered, first, an analytical correction for the horn zone can be obtained by approximating it by a straight wedge, which is more easily done in $2 \mathrm{D}$ than in $3 \mathrm{D}$. The second approach consists in reporting the surface of integration to the vicinity of the contact point onto an encircling skirt, where acoustic velocities are obtained by a local BEM calculation which can be made once for all, independently of the car environment, in terms of transfer functions between the bottom of the tyre and skirt. Figure 6 validated this solution in 2D when only one or 3 points are considered on the front side skirt.

It must be pointed out that a line contact between car and road does not exist in practice and that due to the car loading one should rather consider a surface contact (foot print). Figure 7 is analogue to Figure 3 with a contact length of 32 degrees. The GRIM integration using ICARE is then very good even for a full surface of integration. Figure 8 compares full and deplaced tyre SPL at two different receivers, showing that a significant reduction of tyre noise is achieved for a more realistic tyre.

Last, a more complex 2D situation is considered, where a plate is added to represent the bottom of the car. Figure 9 compares the Green functions at two points $R$ on the tyre for a source at $S$. Fair agreement can be seen. Figure 10 shows the comparison between reference BEM calculation and GRIM calculation with ICARE.

\section{CONCLUSION}

Tyre noise computation is often made for single undeflected tyres. It has been confirmed that the true geometry of the tyre is compulsory. The consideration of full problems can best be obtained by mixing approaches. The use of the ray tracing program ICARE shows great promises. Such an approach relies on the development of tyre models or can be done using laser velocimeter measurements as it has been proved feasible in the case of sound transmission[3].

\section{ACKNOWLEDGEMENT}

The authors are in great debt to Europe funding through the RATIN project which has offered CSTB the means to develop our ideas and to meet top researchers in the field of tyre noise. 


\section{REFERENCES}

1) P. JEAN 1999 Journal of Sound and Vibration 224, 475-487. Coupling integral and geometrical representations for vibro-acoustical problems.1999.

2) P. JEAN 2001. Acta Acustica 87, 236-246 Coupling geometrical and integral methods for indoor and outdoor sound propagation - validation examples.

3) P. JEAN, F. GAUDAIRE, J. MARTIN 2000. Confort automobile et ferroviaire. Le Mans 15-16 Nov. 2000. Applications de la méthode GRIM (Green Ray Integral Method).

4) P. JEAN, J. ROLAND. 2001. Building Acoustics 8, 139-156. Application of the Green Ray Integral Method (GRIM) to sound transmission problems.

5) .F.GAUDAIRE, N.NOE, J.MARTIN, P.JEAN, D.VAN MAERCKE. Congrès SIA. Le Mans 15-16 Nov. 2000. "Une méthode de tirs de rayon pour caractériser la propagation sonore dans les volumes complexes".

6) P. JEAN, Y. GABILLET 1996. Journées DRET. Marseille. A boundary element method program to study 2D noise barriers with ground effects.

7) Y. GABILLET, P. JEAN and J. DEFRANCE 1997. Internoise Budapest. A boundary element formalism for the study of noise barriers.

8) W. KROPP, J. BERILLON 1998. Acustica 84, 681-688. A theoretical model to investigate the acoustic performance of building facades in the low and middle frequency range.

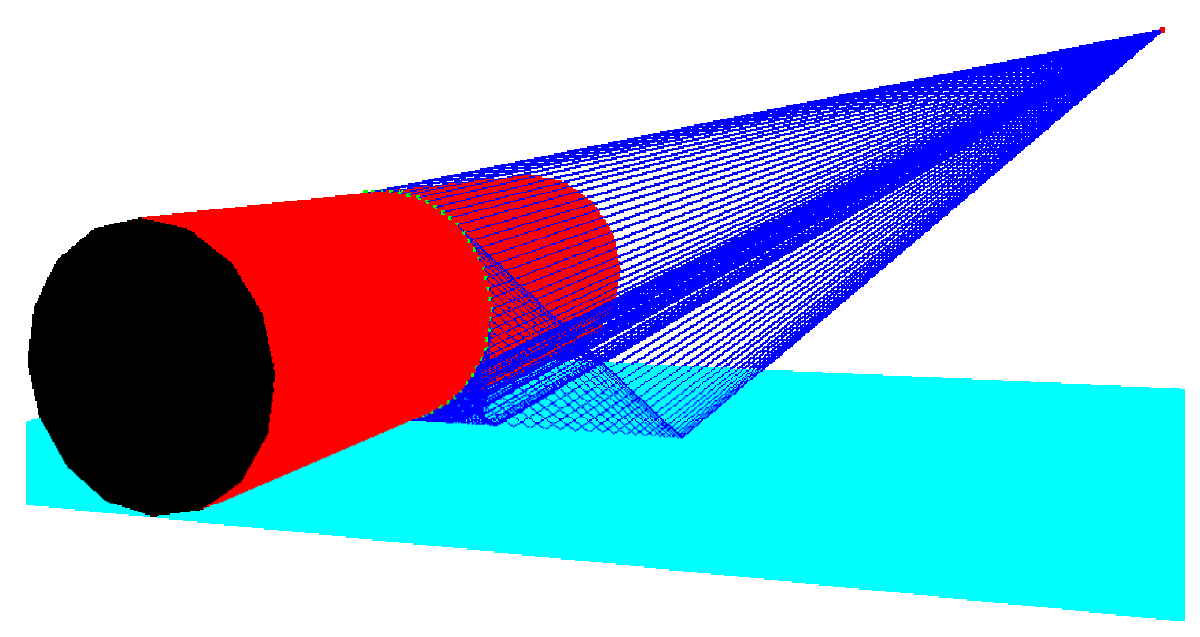

Figure 1. Ray tracing by ICARE on a baffled tyre.

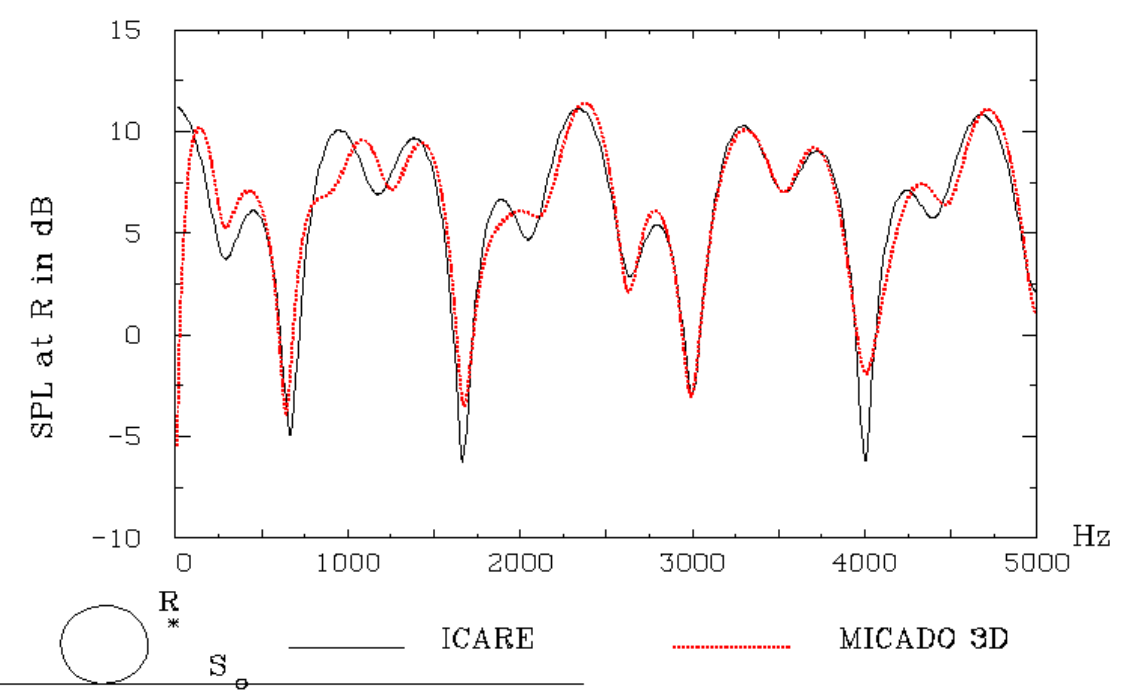

Figure 2. ICARE validation with a rigid cylinder 

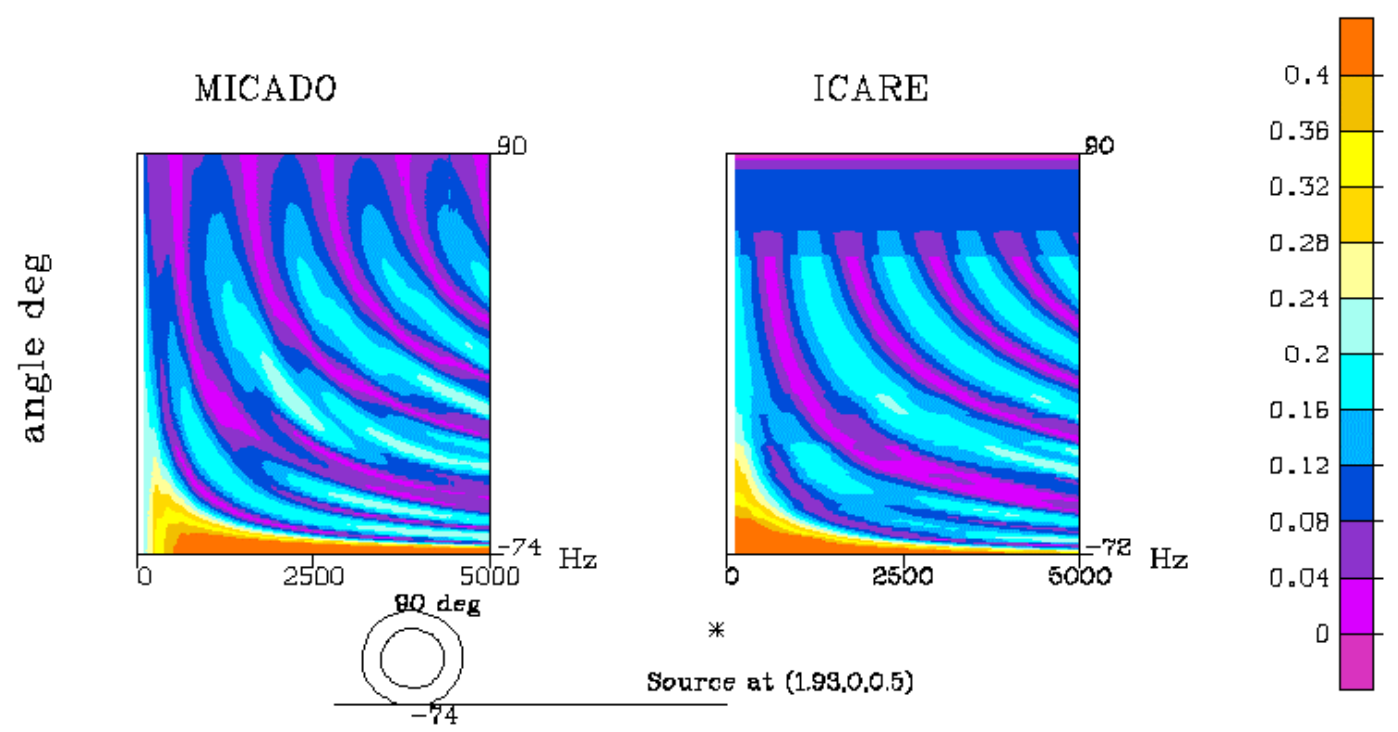

Figure 3. Angular variation of $G$ with frequency. Deflected tyre. Source at $(1.93,0.5)$.
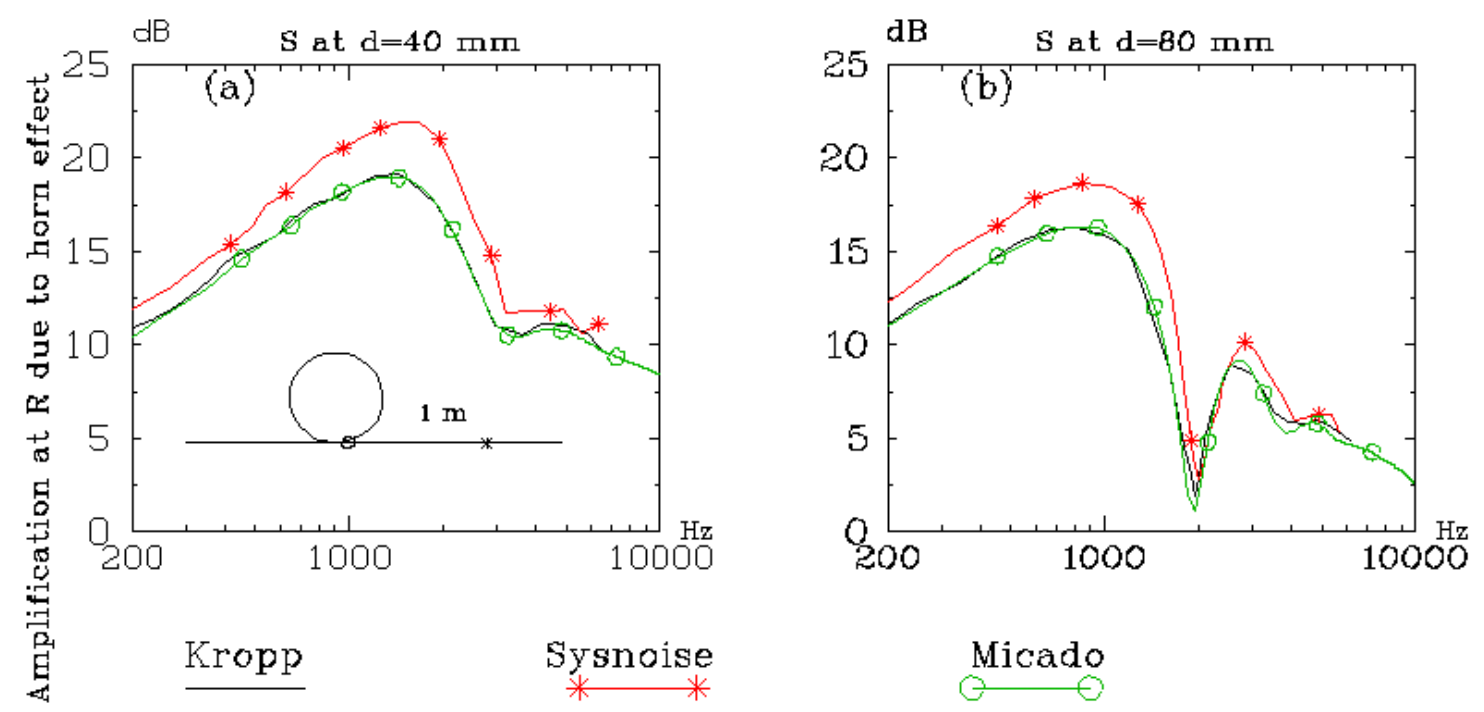

Figure 4. Horn effect on a cylinder. Different models.
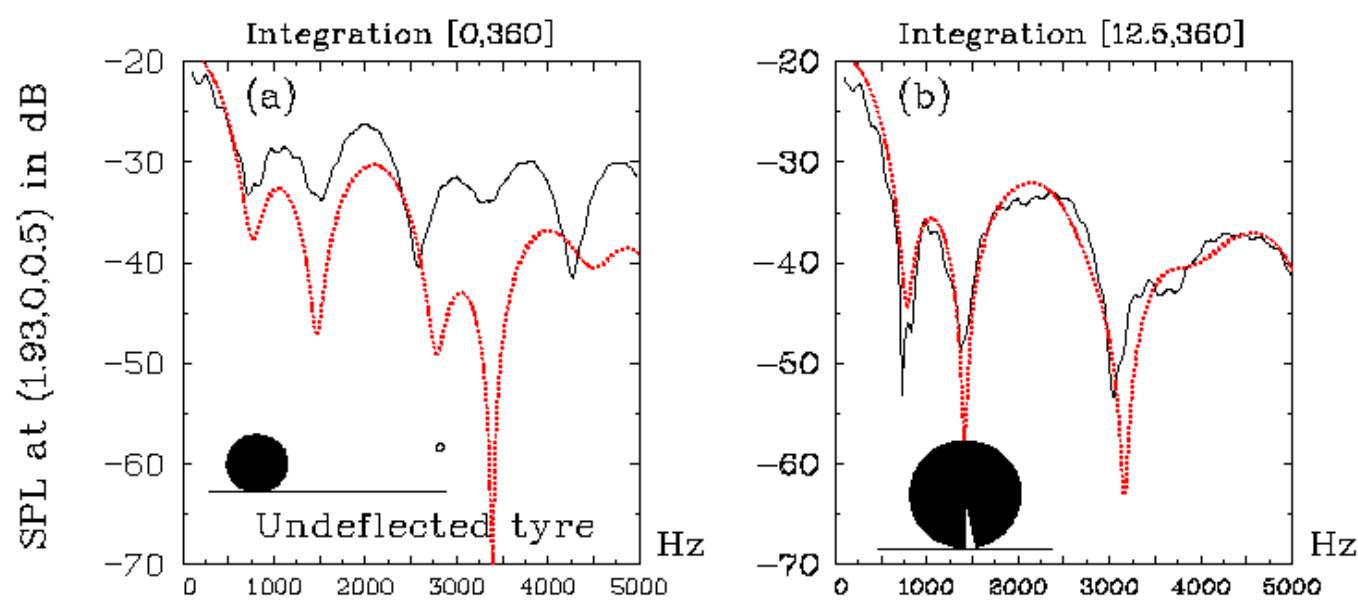

BEM 2.5 D ICARE

Figure 5. GRIM integration: on total or partial tyre surface. Undeflected tyre. 

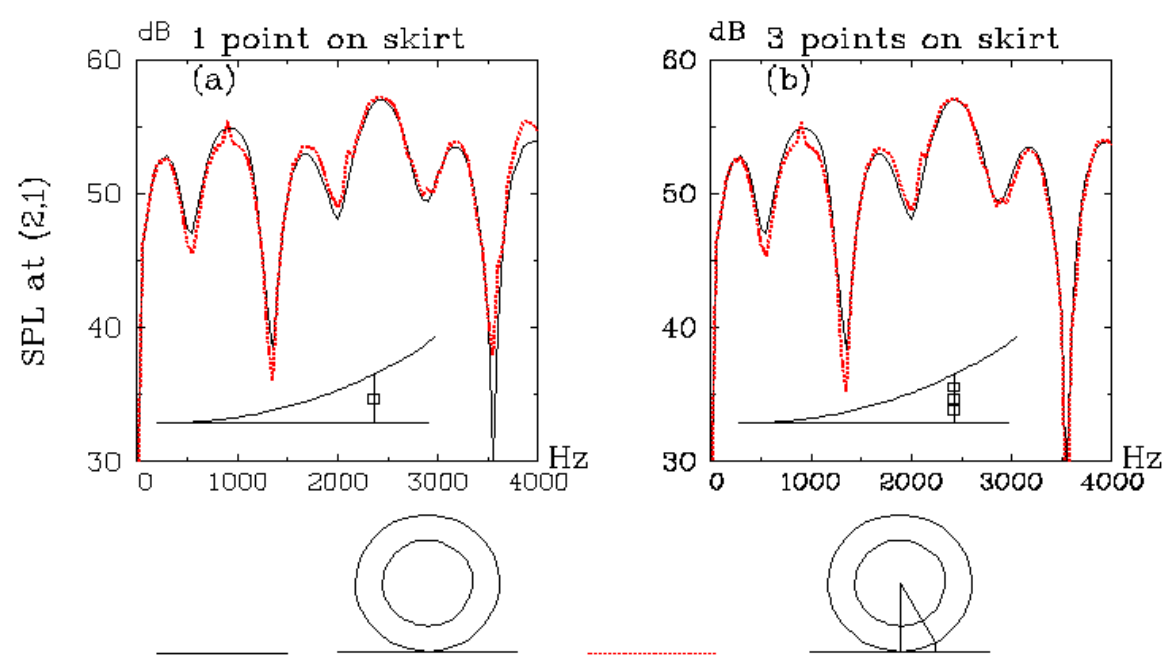

Figure 6. Undeflected tyre. GRIM integration on tyre or on tyre + skirt.
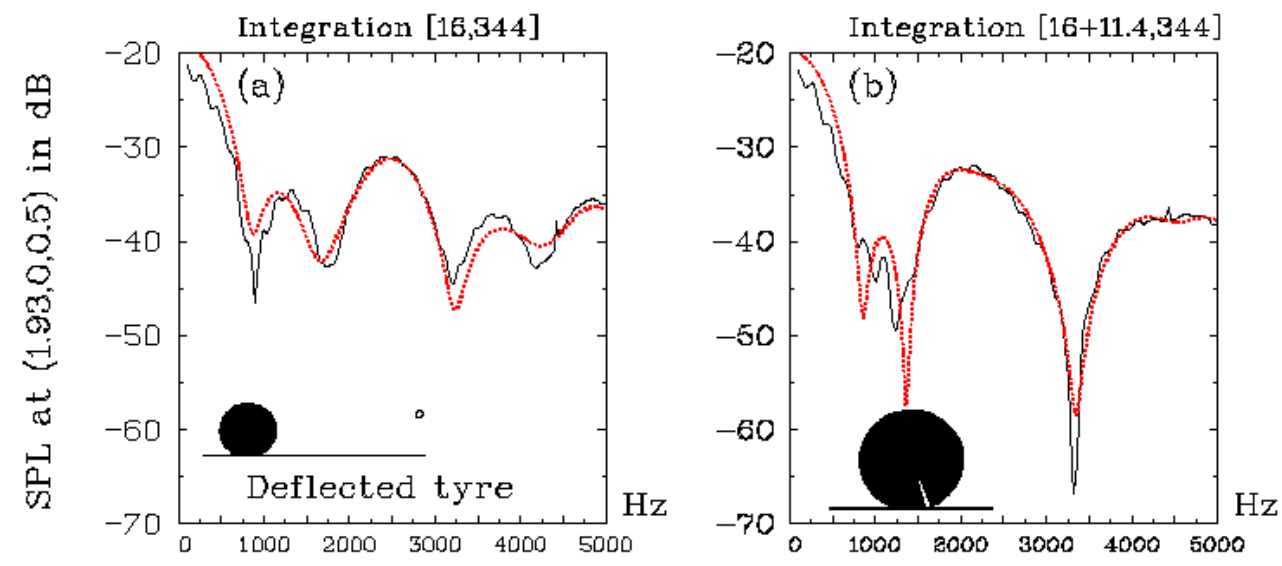

BEM 2.5 D

ICARE

Figure 7.Deflected tyre. GRIM integration.
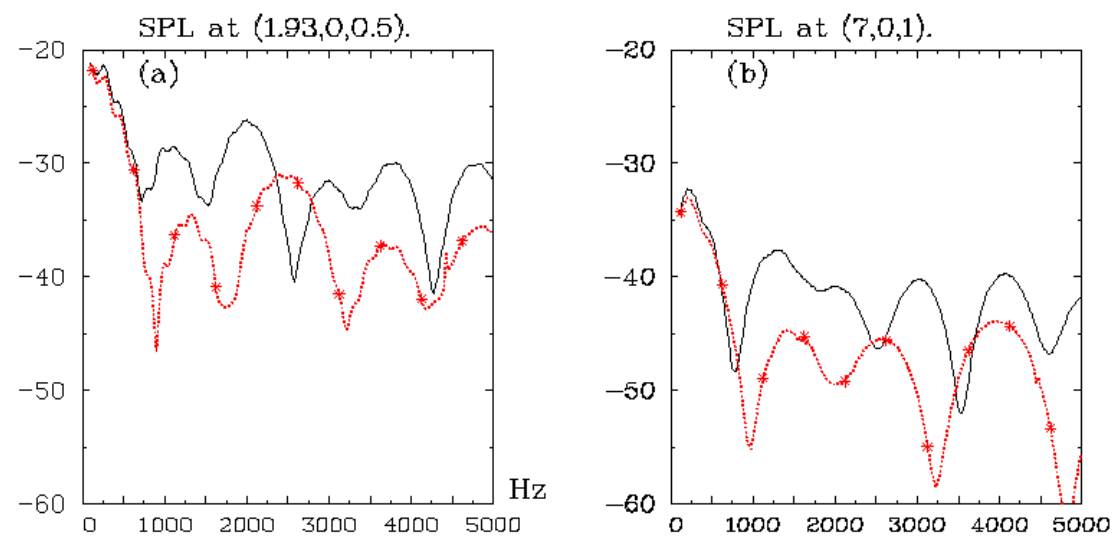

BEM 2.5 D computation.

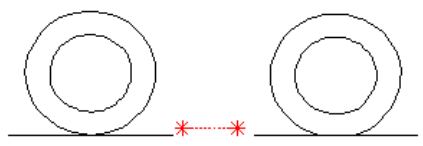

Figure 8. Effect of true tyre shape. 

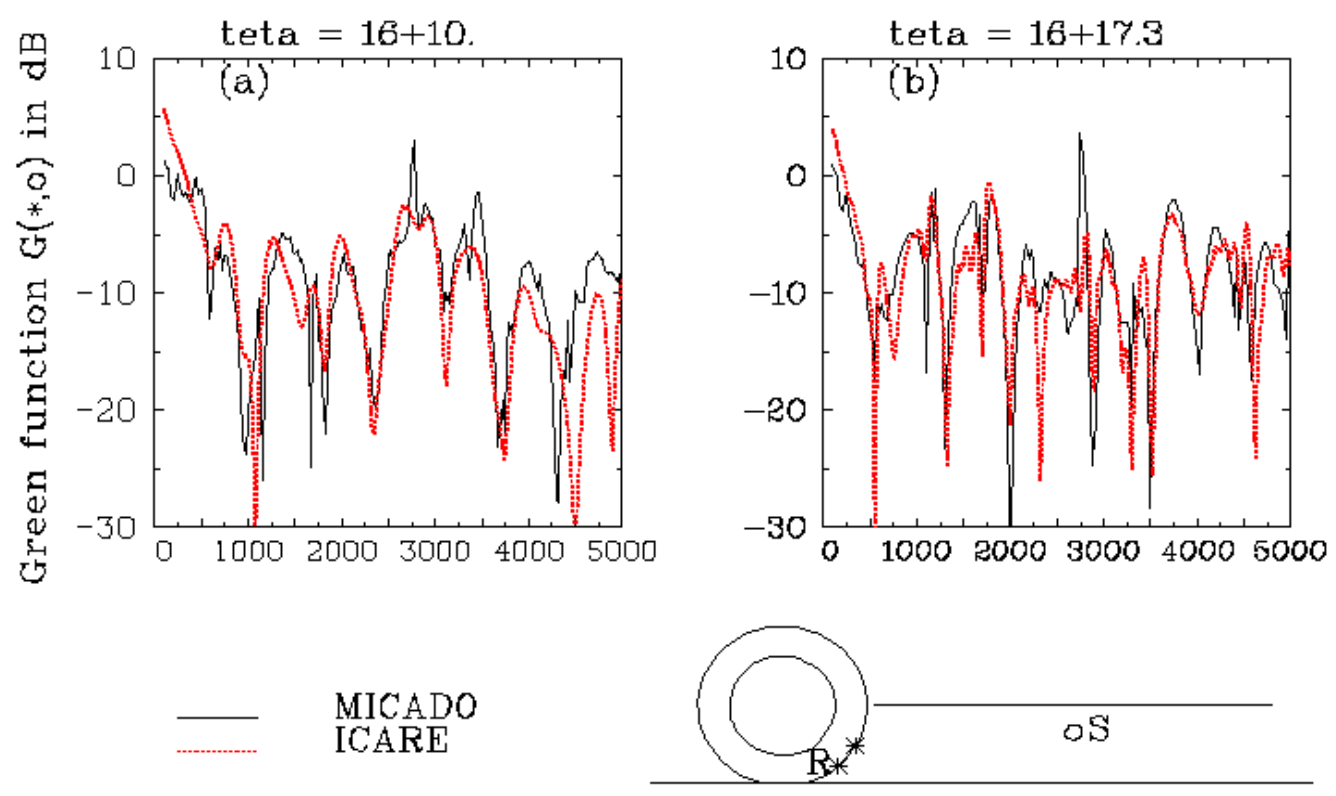

Figure 9.Tyre + reflecting surface. Green functions on tyre.

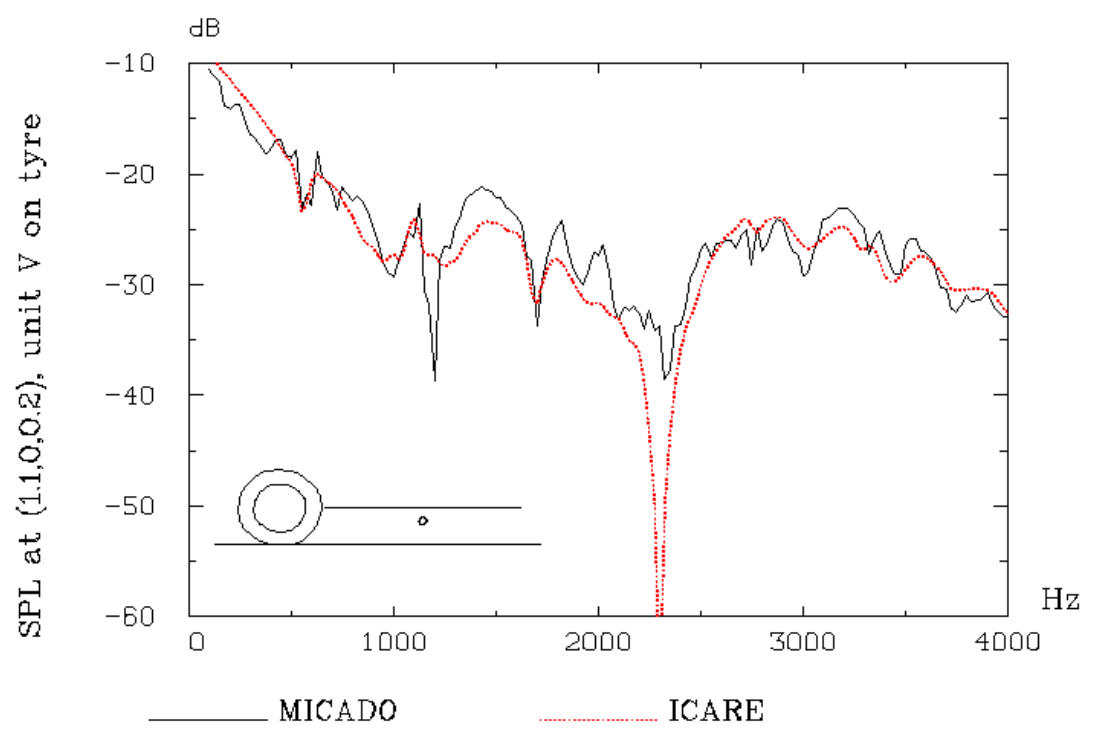

Figure 10. Tyre + reflecting surface. Validation of the GRIM approach with ICARE. 